\title{
Application of Grenade Explosion Method Optimization for Plate-Fin Type Heat Exchanger (PFHE)
}

\author{
R. D. Rakhade, N. V. Patil, M. P. Panchbhai \\ (Department of Mechanical Engineering, KKWIEE\&R, Nashik, India)
}

\begin{abstract}
This paper demonstrates the application of Grenade Explosion Method (GEM) for the design optimization of Plate-Fin Heat Exchanger (PFHE). Maximization of the effectiveness and minimization of the total annual cost are considered as two objective functions. Thermal modelling is done by the $\varepsilon-N T U$ method to estimate the heat exchanger effectiveness and pressure drop. Fin pitch, fin height, the fin offset length, cold stream flow length, no-flow length and hot stream flow length are considered as six design parameters. One application example is presented to demonstrate the effectiveness and accuracy of the Grenade Explosion Method. The results of optimization using GEM are validated by comparing with those obtained by using NonDominated Sorting Genetic Algorithm (NSGA-II).
\end{abstract}

Keywords - Grenade Explosion Method (GEM), Optimization, Non-Dominated Sorting Genetic Algorithm (NSGA-II), Plate-Fin Heat Exchanger (PFHE)

\section{INTRODUCTION}

Plate Fin Heat Exchanger (PFHE) is one of the types of compact heat exchangers which are characterized by a large heat transfer surface area per unit volume of the exchanger. PFHE has high thermal effectiveness, as fins are employed on both sides to interrupt boundary layer growth due to disturbance of flow as well as to increase the heat transfer area. It has high thermal conductivity due to thin thickness of the plate. PFHEs are widely used in gas applications in many industrial power plants, chemical, petrochemical, and petroleum industries. Wavy, offset strip, louver, perforated, and pin fins are some of the commonly used fin surfaces. A typical core of PFHE with rectangular offset strip fin is shown in Figure 1 [1-2]. The design of PFHE involves a large number of variables. Savings of materials, as well as investment cost and operating cost, improving effectiveness, are common objectives for industrial applications of heat exchangers. So to meet the given heat duty requirement and a given set of design constraints, the heat exchanger design optimization is a task full of challenges. Traditional optimization techniques become very time-consuming processes. Recently some authors had applied different non-traditional random search algorithms for the optimization of plate-fin heat exchangers. Xie G.N. et al. [3] used Genetic Algorithm (GA) for optimal design of plate-fin type heat exchangers. The authors had considered minimization of total annual cost and total volume as objective functions and pressure drop as a constraint. A case study was also considered to demonstrate the application of the algorithm. Mishra M. D. et al. [4] used GA to carry out second law based optimization of cross flow platefin heat exchangers. Authors had considered minimization of entropy generation units as an objective function. Sahin B.Y. et al. [5] optimized the design parameters of a heat exchanger with rectangular fins by Taguchi experimental design method. Rao and Patel [6] used Particle Swarm Optimization Algorithm for thermodynamic optimization of PFHE. The authors had considered minimization of a total number of entropy generation units for specific heat duty requirement under given space restrictions and minimization of total volume, and minimization of total annual cost as objective functions and had treated individually. Sanaye and Hajabdollahi [7] used Non-dominated Sorting Genetic-Algorithm (NSGA-II) for multi-objective optimization of PFHE. The authors had considered maximization of effectiveness and minimization of total annual cost as two objective functions. The authors had also performed a sensitivity analysis of change in optimum effectiveness and total annual cost of a change in design parameters of the PFHE. Najafi H. et al. [8] performed multiobjective optimization of PFHE by using GA.

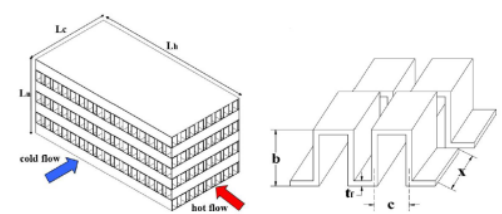

Fig.1. PFHE and rectangular offset strip fin details 


\section{NEED OF OPTIMIZATION}

Due to the globalization of the economy, industries are now facing design challenges not only from their national counterparts but also from the international market. To survive in the step competition, they can no longer afford to adopt just any feasible solution obtained usually by trial and error means; they have to choose an optimal solution which is best with respect to cost, performance, safety, etc. compared to any other solution. Finding optimal solutions to real world engineering, optimization is usually an iterative process limited by available resources. Optimization refers to finding one or more feasible solutions which correspond to extreme values of one or more objectives. The need for finding such optimal solutions in a problem comes mostly from the extreme purpose of either designing a solution for a minimum cost of fabrication, or for maximum possible reliability or other. Because of each extreme property of optimal solutions, particularly in engineering design applications, scientific experiments, and decision making, real world problems often entail the optimization of multiple objectives, if these objectives are conflicting, then no best solution exist, but a set of good compromise solution. There is no single method available for solving all optimization problems efficiently. That's why a number of optimization methods have been developed for solving different types of optimization problems.

\section{GRENADE EXPLOSION METHOD (GEM)}

In this work grenade explosion algorithm (GEM) is used for Plate Fin Heat Exchanger (PFHE) that is the maximization of the effectiveness and minimization of the total annual cost are considered as two objective functions. This method is given most applicability and efficient.The idea of the presented algorithm is based on observation of a grenade explosion, in this technique, the thrown pieces of shrapnel from grenades destruct the objects near the explosion location. Le is the length of the explosion along each coordinate, in which the thrown piece of shrapnel may destruct the objects. loss caused by each piece of shrapnel is calculated. High value for loss per piece of shrapnel in an area indicates there are valuable objects in that area. To make more loss, next grenade is thrown where the greatest loss occurs. Although the objects near grenade's location are more likely to be damaged, the probability of destruction is still kept for further objects by choosing a high value for Le. This process would result in finding the best place for throwing the grenades, even though shrapnel cannot discover this area in early iterations. The loss caused by the destruction of an object is considered as the fitness of the objective function at the object's location. Suppose that $X$ is the current location of a grenade [9]:

$\mathrm{X}=\{\mathrm{Xm}\}, \mathrm{m}=1,2, \ldots, \mathrm{n}$

In which $\mathrm{n}$ is the search space dimension, equal to the number of independent variables. Now Nq pieces of shrapnel are produced by the grenade explosion and destruct objects that are in $\mathrm{Xj}$ location:

$\mathrm{Xj}=\left\{\mathrm{Xm}+\operatorname{sign}\left(\mathrm{r}_{\mathrm{m}}\right) *\left|\mathrm{r}_{\mathrm{m}}\right| \mathrm{p} * \mathrm{Le}\right\}, \mathrm{j}=1,2-----\mathrm{Nq}$

Where $r_{m}$ is a uniformly distributed random number in $[-1,1]$ and $p$ is constant. A high value for $p$ lets pieces of shrapnel search the region near the exploded grenade more accurately, while a low one lets them explore further regions better. Considering eq. (1), it is obvious that exploration for more valuable items performs in an n-dimensional cubic space extended 2Le units along each coordinate and the grenade is located at the center of this cube.According to GEM algorithm, an independent parameter range is scaled to $(-1,1)$. Using eq. (1), some produced shrapnel may collide with objects outside the feasible space. for increase the convergence rate and working area of near-boundary regions more accurately, such a working location is transported to a new location inside the feasible region according to the following scheme:

$B j=r j *(B j-X)+X$

$\mathrm{j}=1$ to $\mathrm{Nq}$ (shrapnel number)

$0<\mathrm{rj}<1$ (random number)

Where $\mathrm{X}^{\prime} \mathrm{j}$ is collision location outside the feasible space and $\mathrm{B}^{\prime}$ is the new location inside the feasible space. A higher value for the explosion range makes it possible to explore further regions for better exploration area, while a lower one lets the grenades focus on the region nearby (better exploitation). Value of exponent $p$ determines the intensity of exploration. This parameter is updated based on the value of $\mathrm{Tw}$, where $\mathrm{Tw}$ is the probability that a produced piece of shrapnel collides an object in an n-dimension hyper-box which circumscribes the grenade's territory.

\section{CASE STUDY -OBJECTIVE FUNCTIONS, DESIGN PARAMETERS AND CONSTRAINTS}

Effectiveness and total annual cost are Two objective functions. Effectiveness $(\epsilon)$ of the cross flow heat exchanger with both fluids unmixed can find out from the table given by Kays and London [10] for obtained values for the heat capacity ratio $\left(\mathrm{C}^{*}=\mathrm{Cmin} / \mathrm{Cmax}\right)$ and the number of heat transfer units (NTU). Total annual cost includes investment cost (the annualized cost of the heat transfer surface area) and operating cost of the compressor to flow the fluid. According to methodology given by Sanaye and Hajabdollahi [7]: 
$\mathrm{C}_{\text {total }}=\mathrm{aC}_{\text {inv }}+\mathrm{C}_{\mathrm{op}}$

$\mathrm{C}_{\text {inv }}=\mathrm{C}_{\mathrm{A}} * \mathrm{~A}^{\mathrm{n}}$

$\mathrm{C}_{\mathrm{op}}=\left\{\mathrm{k}_{\mathrm{el}} \tau\left(\Delta \mathrm{PV}_{\mathrm{t}}\right) / \eta\right\} \mathrm{h}+\left\{\mathrm{k}_{\mathrm{el}} \tau\left(\Delta \mathrm{PV}_{\mathrm{t}}\right) / \eta\right\} \mathrm{c}$

Here $C_{A}$ and $k_{e l}$ are the heat exchanger investment cost per unit surface area and the electricity unit cost respectively, $\mathrm{n}$ is a constant and $\tau$ is the operation hours of the exchanges per year. $\Delta \mathrm{p}, \mathrm{Vt}$ and $\eta$ are pressure drop, volume flow rate and compressor efficiency, respectively. Also, a is annual cost coefficient defined as:

$\mathrm{a}=\mathrm{i} /\left(1-(1+\mathrm{i})^{\wedge}(-\mathrm{y})\right)$

where $\mathrm{r}$ and $\mathrm{y}$ are interest rate and depreciation time in years respectively. The objective function is to minimize: $\mathrm{OF}=-\mathrm{w} 1\left(\varepsilon / \varepsilon_{\max }\right)+\mathrm{w} 2\left(\mathrm{C}_{\text {total }} /\left(\mathrm{C}_{\text {total,min }}\right)\right)$

Parameters like fin pitch (c), fin height (b), fin offset length (x), cold stream flow length (Lc), no-flow length (Ln) and hot stream flow length (Lh) were considered as six design parameters. The constraint are introduced to ensure that the $\alpha=\mathrm{c} / \mathrm{b}, \delta=\mathrm{tf} / \mathrm{x}, \gamma=\mathrm{tf} / \mathrm{c}$ are in the range of $0.134<\alpha<0.997,0.012<\delta<0.048$ and $0.041<\gamma<0.121$. The effectiveness of the present approach using Grenade Explosion Method is assessed by analyzing an application example which is taken from the previous work of Sanaye and Hajabdollahi [7]. Schematic diagram of the PFHE including the details of the rectangular offset strip fins is shown in Figure 1. The rectangular offset strip fin surface is assumed on both the sides of the heat exchanger. The hot gas (hot flow) coming out from the furnace with $1.45 \mathrm{~kg} / \mathrm{s}$ mass flow rate passes through the heat exchanger at $620 \mathrm{~K}$. The fresh air (cold flow) with $1.35 \mathrm{~kg} / \mathrm{s}$ mass flow rate passes through the exchanger at $315 \mathrm{~K}$. Inlet pressure on the hot and cold fluid sides are $180 \mathrm{kPa}$ and $120 \mathrm{kPa}$, respectively. Other operating conditions and the cost function constants are available in reference [7]. The PFHE metal was from stainless steel with thermal conductivity $\mathrm{kw}=18 \mathrm{~W} / \mathrm{m} \mathrm{K}$. So, the objective is to find out the fin geometries and the heat exchanger dimensions i.e. fin pitch (c), fin height (b), fin offset length (x), cold stream flow length (Lc), no-flow length $(\mathrm{Ln})$ and hot stream flow length (Lh) for maximum effectiveness and minimum total annual cost. The objective function given by Equation is subjected to three inequality constraints which are bound by lower and upper limits of the design variables shown in Table 1.

Table 1. Search Range for Decision Variables

\begin{tabular}{|l|l|}
\hline Design Variable & Search Range \\
\hline Fin Pitch(C) & $1-3 \mathrm{~mm}$ \\
\hline Fin Height(b) & $1-7 \mathrm{~mm}$ \\
\hline Fin Length $(\mathrm{x})$ & $2-4 \mathrm{~mm}$ \\
\hline Hot Stream Flow Length $(\mathrm{Lh})$ & $0.2-0.4 \mathrm{~m}$ \\
\hline Clod stream flow Length $(\mathrm{Lc})$ & $0.2-0.4 \mathrm{~m}$ \\
\hline No Flow Length $(\mathrm{Ln})$ & $0.7-1.2 \mathrm{~m}$ \\
\hline
\end{tabular}

Table 2. Comparison of Heat Exchanger Design Geometries

\begin{tabular}{|c|c|c|}
\hline Parameters & $\begin{array}{l}\text { NSGA-II (Sanaye and } \\
\text { Hajabdollahi, 2010) }\end{array}$ & $\begin{array}{l}\text { Grenade } \\
\text { Method }\end{array}$ \\
\hline Fin Pitch, $c(\mathrm{~mm})$ & 2.45 & 1.052 \\
\hline Fin Height, $b(\mathrm{~mm})$ & 3.20 & 7.682 \\
\hline Fin Length, $x(\mathrm{~mm})$ & 3.45 & 2.657 \\
\hline Hot Stream Flow Length, $L_{h}(\mathrm{~m})$ & 0.39 & 0.3669 \\
\hline Cold Stream Flow Length, $L_{c}(\mathrm{~m})$ & 0.39 & 0.3499 \\
\hline No-Flow Length, $L_{n}(\mathrm{~m})$ & 1.18 & 0.8338 \\
\hline Effectiveness, $\varepsilon$ & 0.8 & 0.8 \\
\hline Investment cost, $C_{\text {in }}$ & 2435.7 & 2330.46 \\
\hline Operating cost, $C_{\sigma p(\$)}$ & 388.59 & 289.12 \\
\hline Total annual cost, TAC (\$) & 784.88 & 668.39 \\
\hline Payback period, $y$ (days) & 70 & 66.48 \\
\hline
\end{tabular}

The codes for Grenade Explosion Algorithm are written in MATLAB. Numbers of trials are conducted to decide the operating parameters of the algorithm to obtain the optimum solution. Table 2 shows the optimized values of the design variables of the considered example using Grenade Explosion Algorithm for $\epsilon=0.8$ and its comparison with the results obtained by previous researchers using NSGA-II [7]. Results show 12.62\% reduction in total annual cost with new geometry obtained using Grenade Explosion Algorithm. Also for given volume flow rate of fuel, $1.71 \%$ reduction is observed in the estimated payback period (y). 


\section{CONCLUSION}

The present study demonstrates the successful application of Grenade Explosion Algorithm for multiobjective optimization of a plate fin heat exchanger considering together the maximization of effectiveness and minimization of total annual cost as the objective function. In the present work six design variables, fin pitch, fin height, fin offset length, cold stream flow length, hot stream flow length and no-flow length are optimized under given a set of constraints. Results obtained for the application example using Grenade Explosion Algorithm are compared with NSGA-II approach given by earlier researchers. Improvement in the results is observed using Grenade Explosion Algorithm compared to NSGA-II, showing the potential in the application of Grenade Explosion Algorithm for plate-fin heat exchanger optimization.

\section{REFERENCES}

[1] R.K.Shah,D.P.Sekulic,Fundamentals of Heat Exchanger Design(John Wiley \&Sons, New York, 2003).

[2] Hesselgreaves, J.E.,Compact Heat Exchangers: Selection, Design, and Operation(Pergamon, New York, 2001).

[3] G.N Xie,B.Sunden,Q.W.Wang,Optimization of compact heat exchangers by a genetic algorithm,Applied Thermal Engineering,28(8-9), 2008, 895-906.

[4] M.Mishra, P.K.Das,S. Sarangi,Second law based optimization of cross-flow plate-fin heat exchanger design using a genetic algorithm,Applied Thermal Engineering,29(14-15),2009, 2983-2989.

[5] B.Sahin, K.Yakut, I. Kotcioglu, C.Celik,Optimum design parameters of a heat exchanger, Applied Energy, 82(1), 2005, 90-106.

[6] R.V.Rao,V.K.Patel, Thermodynamic optimization of cross flow plate-fin heat exchanger using a particle swarm optimization algorithm,International Journal of Thermal Sciences,49(9), 2010, 1712-1721.

[7] S.Sanaye, H.Hajabdollahi, Thermal-economic multi-objective optimization of plate fin heat exchanger using genetic algorithm,Applied Energy, 87(6),2010, 1893-1902.

[8] H.Najafi, B. Najafi,P.Hoseinpoori, Energy and cost optimization of a plate and finheat exchanger using genetic algorithm. Applied Thermal Engineering,31(10), 2011,1839-1847.

[9] A.Ahrari, Grenade Explosion Method-A novel tool for optimization of Multimodal functions, Applied Soft Computing,10(4), 2009,1132-1140.

[10] W.M.Kays, L.A. London, Compact Heat Exchangers(McGraw Hill, New York, 1964). 